\title{
Cinna Lomnitz Aronsfrau. In memoriam
}

\author{
Arturo Iglesias Mendoza ${ }^{1 *}$
}

Iglesias Mendoza, A. Cinna Lomnitz Aronsfrau. In memoriam. Investigación y Ciencia de la Universidad Autónoma de Aguascalientes. Número 70: 102-105, enero-abril 2017.

... Allí, en el comienzo de la primavera marina,

cuando el ave asustada y hambrienta persigue a la nave

y en la sal apacible del cielo y el agua aparece el aroma

del bosque de Europa, el olor de la menta terrestre,

supimos, amada, que Chile sufría quebrado por un terremoto. (Neruda, 1967)

"...la ciudad desfallece

bajo el quinto sol,

no la castiga el agua,

ni el tigre,

ni la furia del viento,

ni tan siquiera el fuego ardiendo

en el plumaje sagrado

del crepúsculo,

sino el socavón

de sus entrañas..." (Yáñez, 1985).

¿Cuántas personas habrán tenido la desventura de haber vivido en carne propia el sismo más grande registrado hasta ahora en el mundo y también el sismo más destructivo que haya ocurrido en México? Seguramente no muchas, pero aun menos son aquellas cuya vida giró alrededor de los sismos. Si por casualidad hubo varias, al menos tuve la fortuna de conocer a una de ellas: Cinna Lomnitz nació en Colonia, Alemania, en 1925, 12 años antes de migrar a Chile. Describe su migración así:

A principios de 1933, pocas semanas después de la ascensión de Hitler al poder, emigré de Alemania ya que mi padre, por consejo de su mejor amigo, un miembro destacado del Partido Nazi, había resuelto autoexiliarse.

1 Departamento de Sismología, Instituto de Geofísica, Universidad Nacional Autónoma de México, México.

* Autor para correspondencia: arturo@geofisica.unam.mx



Dr. Cinna Lomnitz Aronsfrau. Fotografía tomada de Conacyt Agencia Informativa.

Tenía yo siete años y no había oído hablar de México. Un par de años más tarde, pasábamos una estancia veraniega en la playa de Knokke, en la Riviera belga. Mi padre, un joven abogado de mucho éxito, estaba pensando rehacer su vida lo más lejos posible de una Europa que se precipitaba al abismo de una guerra... (Lomnitz Aronsfrau, 2003, párrs. 21 y 22)

Estudió Ciencias Físicas y Matemáticas en la Universidad de Chile y se graduó en 1948. Hizo una maestría en la Universidad de Harvard con el tema de mecánica de suelos. Ahí estudió con Karl von Terzaghi, reconocido como uno de los padres de la mecánica de suelos. Lomnitz escribió un texto titulado "Recuerdo 
a Terzaghi", en el que hace un extraño homenaje a su maestro, del cual transcribo unas líneas: "...El hecho es que el profesor Karl von Terzaghi ejercía sobre nosotros los estudiantes una fascinación letal. Lunes, miércoles y viernes estábamos todos bien sentaditos en el auditorio semicircular de ingeniería de Harvard, esperando que apareciera cual malévolo vampiro..." (Lomnitz Aronsfrau, 1993, párr. 1).

Fue becado por la UNESCO para estudiar el doctorado en el California Institute of Technology (CALTECH), en donde obtuvo el grado de doctor en 1955. Ahí convivió con grandes profesores: "Eran los años cincuenta y en el Caltec estaba el trío de sismólogos más destacados del mundo: Charles $\mathrm{F}$. Richter, Beno Gutenberg y Hugo Benioff, ifue una suerte doctorarme allí!..." (Lomnitz Aronsfrau en Salcedo Meza, 1999, párr. 2).

En numerosos textos, Lomnitz recuerda sus experiencias con los grandes profesores de la época que, sin duda, trazaron no sólo su trayectoria científica sino también su vida. Un par de ejemplos se incluyen a continuación.

\section{El primero:}

\begin{abstract}
Hugo Benioff era otro personaje genial del Caltech; le gustaba inventar instrumentos diversos: desde guitarras eléctricas hasta sismógrafos. Creo que él fue el teórico más importante de ese tiempo. Me propuso el tema de mi tesis doctoral, ya que él creía que la forma como se deforman las rocas tiene que ver con la predicción de los sismos. Pero en mi tesis demostré que no era así. Él se desilusionó, pero así es la ciencia... (Lomnitz Aronsfrau en Salcedo Meza, 1999, párr.. 4)
\end{abstract}

\section{Otro ejemplo:}

Poco faltó para que me inscribiera con Dick Feynman. Pero Anderson ya se había ganado el premio Nobel y Feynman todavía no. Además, Feynman era muy excéntrico; iniciaba sus clases con un redoble de tambor para despertar a los estudiantes. Esas fueron las clases de física que se hicieron famosas en todo el mundo durante el siglo veinte. (Lomnitz Aronsfrau en Urrutia Fucugauchi, 2016, párr. 5)

Después de doctorarse pasó dos años más en Caltech contratado por Richter como su asistente en una estancia postdoctoral. En 1957 regresó a Chile como director fundador del Instituto de Geofísica de la Universidad de Chile.
Cinna Lomnitz participó en una expedición oceanográfica en 1959. El líder científico de esa expedición era Maurice Ewing, uno de los geofísicos más notables de la historia. Cuenta Lomnitz:

\begin{abstract}
...Maurice Ewing, un texano enorme, nunca alzaba la voz. Lo conocí después de su segundo infarto, cuando me invitó a formar parte de la Expedición 15 de su barco oceanográfico, el Vema, un yate de tres palos modificado para servir de laboratorio flotante. Ewing trabajaba como un endemoniado. Por órdenes del Doc (así le decíamos), se izaba la bandera pirata en alta mar. Entonces no había más ley que la suya. Ewing fue el último de los grandes exploradores y descubridores de la mar océano... (Lomnitz Aronsfrau, 2003, párr. 3)
\end{abstract}

En la mañana del sábado 21 de mayo de 1960 comenzó una serie de terremotos que sacudieron el sur de Chile. Entre las 6 a.m. y la 1 p.m. se reporta en los catálogos internacionales un sismo de magnitud 8.6, uno de 8.1 y uno de 7.1 , además de un número importante de temblores de menor magnitud. Lomnitz viajó apenas el día siguiente por avión a la Ciudad de Concepción, una ciudad ubicada a más de 400 $\mathrm{km}$ de distancia de Santiago y cercana a la zona epicentral de los sismos ocurridos el día anterior. Llegó al aeropuerto de Concepción cerca de las 3:15 p.m., cuando ocurrió el sismo más grande de la historia sísmica instrumental: $300 \mathrm{~km}$ al sur de Concepción, cerca de la Ciudad de Valdivia, se desató un terremoto de magnitud 9.5. Lomnitz describe el movimiento:

\begin{abstract}
A las 3:15 del día 22 de mayo de 1960 me encontraba caminando a lo largo del aeropuerto de la Ciudad de Concepción cuando empecé a sentir un enorme movimiento muy lento, los árboles se movían de esta forma (circular) e incluso había aviones en la pista, sin gente, y se movían de un lado para otro... rodando. El epicentro estaba a más de $200 \mathrm{~km}$ de distancia, pero el movimiento era muy impresionante. (Lomnitz Aronsfrau en UNAM, s. f.)
\end{abstract}

De 1964 a 1968 fungió como jefe de la red sismológica de la Universidad de California-Berkeley. Lomnitz recuerda aquella época de su vida, entrevistado en 2015:

Fue una vivencia extraordinaria. En esa época se empezó a usar algo que después no cundió mucho, los bailes (encueradosı. Se prestaban ciertas viviendas y los invitados tenían que ajustarse a modalidades muy interesantes. Por ejemplo, al bailar no era buena onda fijarse en lo que estaban haciendo las demás parejas. Era una mezcla de puritanismo con ideas muy avanzadas... (Lomnitz Aronsfrau en Saavedra, 2016, párr. 9) 
IIVESTIGACIÓn Y CIERGIA DE LA UחIVERSIDAD AUTÓnOMH

104 DE RGUASCALIERTES

En esa época también fue parte de la misión patrocinada por la UNESCO "Reconocimiento sismológico: Terremoto del 17 de octubre de 1966 destructor en el Perú" que compartió con el Dr. Luis Esteva Maraboto, brillante ingeniero sísmico y en su momento, Jefe del Departamento de Estructuras del Instituto de Ingeniería de la UNAM. Probablemente con esa experiencia empezaron los contactos con México. En 1968, tras invitaciones de Emilio Rosenblueth y Roger Díaz de Cossío, se incorpora al Instituto de Geofísica de la UNAM, encabezado por el Dr. Ismael Herrera Revilla, quien consiguió para Lomnitz el nombramiento más alto posible: Investigador Titular C.

En sus primeros años en México, Lomnitz contribuyó sustancialmente a la modernización de la red de estaciones sismológicas proponiendo un novedoso sistema de telemetría, diseñado y construido en nuestro país, que permitía por primera vez, tener señales sísmicas en tiempo real de manera remota. Es así como se constituye la Red Sismológica Mexicana de Apertura Continental (RESMAC). La misma fue uno de los grandes orgullos de Lomnitz. Él y sus colaboradores de la época frecuentemente platicaban con emoción de los diseños electrónicos y el despliegue de la red:

\footnotetext{
Nuestros técnicos iban al otro lado, y regresaban con los bolsillos llenos de transistores especiales que no se encontraban en el comercio. La verdad, era la única manera de construir un sistema avanzado de este tipo.

[...]

Fue la primera red sísmica de telemetría. Anteriormente, cada estación debía tener su cuidador que enviaba los sismogramas a México, y los datos llegaban tarde, mal y nunca. RESMAC no tenía necesidades de personal en las torres, y la red de microondas llegaba a todo el país y teníamos excelente cobertura. (Lomnitz Aronsfrau en Saavedra, 2016, párrs. 13 y 15)
}

En este texto empecé hablando de la tremenda coincidencia de que un sismólogo como Cinna Lomnitz estuviera presente en dos sismos de los más relevantes. Pero más allá de la coincidencia, algunos sismólogos tienen una suerte de atracción fatal por los temblores. La fotoaxia positiva es la predisposición de algunos seres vivos de sentirse atraídos hacia la luz. Algunos de ellos no pueden evitar acercarse a los focos, que en ocasiones los conducen a situaciones fatales.
El Dr. Lomnitz, al parecer, no podía evitar acercarse a la fuente de los grandes temblores. En el siguiente texto habla de su experiencia durante el sismo del 19 de septiembre de 1985:

La casa, una de las más antiguas de San Angel, empezó a crujir y a mecerse suavemente a las 7:19 de la mañana [...] La sismología ha avanzado desde entonces, y hoy le pondríamos membrete al fenómeno - "intensidad seis en la escala de Mercalli", pensé-. Se trataba de un sismo lejano, obviamente.

Al llegar al Instituto de Geofísica encontré que ya habían llegado varios compañeros. El sismograma se veía enorme y el teléfono estaba muerto: no había manera de consultar con los colegas americanos. Pero hicimos una buena localización preliminar: epicentro frente a Lázaro Cárdenas, Michoacán. Ni modo, vamos para allá. (Lomnitz Aronsfrau, 2005, párrs. 1 y 2)

Bajo el efecto de una especie de fotoaxia positiva, Lomnitz aborda, lo más rápido posible, una avioneta con rumbo a Zihuatanejo, zona cercana al epicentro. En su visita observó las manifestaciones propias de un gran temblor:

\begin{abstract}
Sobrevolando la costa noté que algo había cambiado. El nivel de la costa había subido un poco. Sí, efectivamente, la línea de marea parecía haberse retirado. ¿ Cuánto será? Un metro o dos. Ya en Lázaro Cárdenas, ciudad de 150 mi habitantes situada en la desembocadura del río Balsas, en suelos muy poco prometedores, el daño sísmico resultó mínimo. "Parece que no hay víctimas..." (Lomnitz Aronsfrau, 2005, párr. 4)
\end{abstract}

Puedo imaginar el desconcierto del Dr. Lomnitz algunas horas después: "En la noche vino la sorpresa. La televisión regresó al aire y pudimos ver con asombro la tremenda destrucción que se había producido en la ciudad de México, a 400 kilómetros de distancia..." (Lomnitz Aronsfrau, 2005, párr. 5). «Fue desastroso, se cayeron 400 edificios, todos en la zona del Lago. No se cayó nada en las Lomas, todo el daño estuvo concentrado en la antigua zona de la Laguna de México..." (Lomnitz Aronsfrau en Saavedra, 2016, párr. 17).

Jaime Urrutia, en un excelente texto biográfico, reflexiona: "Los efectos del sismo de 1985 fueron peores de lo que nadie se imaginaba. A partir de este momento, Lomnitz deja de lado sus diversas líneas de investigación y se dedica exclusivamente a desentrañar las causas de esta catástrofe..." (Urrutia Fucugauchi, 2016, párr. 18). 
En 1990 optó por la ciudadanía mexicana y obtuvo una gran cantidad de reconocimientos: Premio Nacional de Ciencias y Artes (1995), Premio Universidad Nacional Autónoma de México (1997), Investigador Emérito del Sistema Nacional de Investigadores, Investigador emérito del Instituto de Geofísica (2002) y "Ángel de la Ciudad" por la Jefatura de Gobierno de la Ciudad de México (2015).

En la vida de Lomnitz no todo fue conocimiento, aventura y reconocimiento. Hubo también momentos devastadores. Por ejemplo, cuando una terrible enfermedad condujo a la muerte a su hijo, el muy destacado científico Dr. Jorge Lomnitz Adler. Al respecto, Cinna escribió: "...Cuando muere un científco, el país está de duelo. Si muere en la flor de la edad, antes de alcanzar la plenitud que sus talentos nos prometían, hay consternación en el mundo de la ciencia. [...] Era mi hijo..." (Lomnitz Aronsfrau, 1994, párrs. 1 y 2).

"Hay ciertas cosas que no tolero, como la violencia y la guerra. Soy muy pacífico y sólo me enojo cuando he acumulado disgustos" (Lomnitz Aronsfrau en Salcedo Meza, 1999, cuadro de datos al final del texto).

El pasado 7 de julio de 2016 murió el Dr. Cinna Lomnitz. Acababa de cumplir 91 años. Creo que no se puede decir que estaba en la flor de la edad, pero es clara la consternación en el mundo de la ciencia. Descanse en paz.

Ciudad de México, 28 de septiembre de 2016

\section{LITERATURA CITADA}

- SALCEDO MEZA, C. ¿̇uién es? Cinna Lomnitz. ¿ Cómo ves?, 10, septiembre de 1999.

- UNAM-INSTITUTO DE GEOFÍ́SICA. Entrevista a Cinna Lomnitz para el video conmemorativo de los 100 años del Servicio Sismológico Nacional. [Material videograbado]. México: Autor, s.f.

\section{De páginas electrónicas}

- CONACYT Conacyt Agencia Informativa. Cinna Lomnitz Aronsfrau [Fotografía]. Recuperado de http://conacytprensa. $\mathrm{mx} /$ index.php/sociedad/personajes/192-cinna-lomnitzaronsfrau

- LOMNITZ ARONSFRAU, C. El próximo temblor: ¿Estamos preparados? Nexos, 1 de noviembre de 2005. Recuperado de http://www.nexos.com.mx/?p=11708

- LOMNITZ ARONSFRAU, C. Gloria y el TLC. Nexos, 1 de septiembre de 1993. Recuperado de http://www.nexos.com.mx/?p=6873
- LOMNITZ ARONSFRAU, C. La pasión científica. Nexos, 1 de abril de 2003. Recuperado de http://www.nexos.com.mx/?p=10747

- LOMNITZ ARONSFRAU, C. Un corazón intrépido. Nexos, 1 de marzo de 1994. Recuperado de http://www.nexos.com. $m x / ? \mathrm{p}=6996$

- SAAVEDRA, D. Fallece el sismólogo Cinna Lomnitz. Reforma, 7 de julio de 2016. Recuperado de http://www.reforma.com/ aplicacioneslibre/articulo/default.aspx?id=8881 19\&md5=887e 145e913d12d240060a6507be3744\&ta=0dfdbac $11765226904 \mathrm{cl}$ 6cb9ad1b2efe

- URRUtia fuCugauCHI, J. Cinna Lomnitz Aronsfrau. Boletín AMC/152/16, 8 de julio de 2016. Recuperado de http://www. comunicacion.amc.edu.mx/comunicados/1-cinna-lomnitzaronsfrau 